\title{
Evaluation of the efficacy of the metal artifact reduction algorithm in the detection of a vertical root fracture in endodontically treated teeth in cone-beam computed tomography images: An in vitro study
}

\section{Ocena skuteczności algorytmu redukującego artefakty pochodzące od elementów metalowych w rozpoznawaniu pionowego złamania korzeni zębów leczonych endodontycznie w tomografii stożkowej - badanie in vitro}

\author{
Samira Saati ${ }^{1, A, E}$, Amir Eskandarloo ${ }^{1, A}$, Alireza Falahi2, ${ }^{2}$, Leili Tapak ${ }^{3,4, C}$, Bahareh Hekmat ${ }^{5, A, B, D-F}$ \\ 1 Department of Oral and Maxillofacial Radiology, Hamadan University of Medical Sciences, Iran \\ ${ }^{2}$ Department of Biomedical Engineering, Hamadan University of Technology, Iran \\ ${ }^{3}$ Department of Biostatistics, School of Public Health, Hamadan University of Medical Sciences, Iran \\ ${ }^{4}$ Modeling of Non-Communicable Diseases Research Center, Hamadan University of Medical Sciences, Iran \\ ${ }^{5}$ Department of Oral and Maxillofacial Radiology, School of Dentistry, Zanjan University of Medical Sciences, Iran \\ A - research concept and design; $\mathrm{B}$ - collection and/or assembly of data; $\mathrm{C}$ - data analysis and interpretation; \\ $D$ - writing the article; $E$ - critical revision of the article; $F$ - final approval of the article
}

\section{Address for correspondence \\ Bahareh Hekmat}

E-mail: bahar_hekmat70@yahoo.com

Funding sources

None declared

Conflict of interest

None declared

Received on March 26, 2019

Reviewed on April 21, 2019

Accepted on June 6, 2019

Published online on December 30, 2019

Cite as

Saati S, Eskandarloo A, Falahi A, Tapak L, Hekmat B. Evaluation of the efficacy of the metal artifact reduction algorithm in the detection of a vertical root fracture in endodontically treated teeth in cone-beam computed tomography images: An in vitro study. Dent MedProbl. 2019;56(4):357-363. doi:10.17219/dmp/109902

DOI

$10.17219 / \mathrm{dmp} / 109902$

Copyright

๑ 2019 by Wroclaw Medical University

This is an article distributed under the terms of the

Creative Commons Attribution 3.0 Unported License (CC BY 3.0)

(https://creativecommons.org/licenses/by/3.0/)

\begin{abstract}
Background. Three-dimensional (3D) cone-beam computed tomography (CBCT) scans play an important role in dental diagnostics and treatment planning, especially in detecting vertical root fractures (VRFs). However, artifacts caused by high-density dental materials can negatively affect the quality of CBCT images by decreasing contrast and masking structures.

Objectives. The aim of this study was to assess the efficacy of artifact removal software in detecting VRFs in endodontically treated teeth on CBCT scans.

Material and methods. This study evaluated 70 endodontically treated single-rooted teeth. Half of the teeth were cracked by introducing a wedge into the canal and tapping gently with a hammer; the rest remained untouched as a control group. The teeth were then mounted in a bovine rib bone. Soft tissue was simulated using red dental wax. Cone-beam computed tomography scans were taken using the NewTom ${ }^{\circledR}$ 3G, ProMax ${ }^{\circledR} 3 \mathrm{D}$ and $\mathrm{Crane} \mathrm{x}^{\circledR} 3 \mathrm{D}$ CBCT systems, and the MATLAB software was applied. The images were evaluated by 2 oral and maxillofacial radiologists, and the results were recorded in a checklist. The data was analyzed using the $k$ coefficient, McNemar's test and the receiver operating characteristic (ROC) curves.
\end{abstract}

Results. A significant inter-observer agreement was noted between the 2 observers in detecting VRFs using all CBCT systems. In all systems, the use of the MATLAB software improved the detection of VRFs, but the difference was not significant in the NewTom $3 G(p=0.119)$ and ProMax 3D $(p=0.455)$ systems. However, the difference was significant in the Cranex 3D system $(p=0.039)$.

Conclusions. The MATLAB artifact removal software can enhance the detection of VRFs on CBCT scans to some extent.

Key words: cone-beam computed tomography, artiffact, fracture, endodontically treated

Słowa kluczowe: tomografia stożkowa, artefakt, złamanie, leczony endodontycznie 


\section{Introduction}

Cone-beam computed tomography (CBCT) is an imaging modality with several applications and an increasing popularity in dentistry. It provides three-dimensional (3D) images and is commonly used in implantology, orthodontics, and oral and maxillofacial surgery. The majority of CBCT systems are capable of producing high-resolution images that visualize fine anatomical structures. ${ }^{1,2}$ The advantages of $\mathrm{CBCT}$ compared to conventional radiography have increased its use in many dental fields. ${ }^{3,4}$ The main advantage of $C B C T$ in the detection of dental lesions is that it provides superior 3D images of the teeth and periodontal tissue compared to two-dimensional (2D) radiography. Moreover, the patient radiation dose in CBCT is lower than that in multi-detector computed tomography (MDCT). ${ }^{5,6}$

Exposure parameters, such as field of view (FOV) and voxel size, can affect the quality of CBCT images. ${ }^{7}$ Cone-beam computed tomography systems with a small FOV provide images of higher quality and lower artifact incidence compared to CBCT systems with a large FOV. ${ }^{8,9}$ Cone-beam computed tomography has been suggested as an efficient diagnostic modality for complex root canal treatment and for the assessment of the root canal system. ${ }^{10,11}$ Recently, CBCT has been recommended as an efficient modality for the detection of vertical root fractures (VRFs) due to its numerous advantages. ${ }^{12}$ Vertical root fractures are often detected by noticing a radiolucent fracture line. An X-ray beam needs to be parallel to the fracture line; otherwise a radiolucent trace is not visible on radiographs. ${ }^{13}$

Artifacts are the errors or distortions of the image reconstruction data. ${ }^{14}$ Artifacts caused by high-density materials affect the quality of $\mathrm{CBCT}$ images by decreasing contrast and masking structures, which complicates diagnosis. ${ }^{13}$ Gutta-percha, root-filling materials and metal posts can cause streak artifacts, which mimic the fracture lines and cause false positive results, hindering the detection of root fractures. ${ }^{3,7}$

Several methods have been suggested to reduce CBCT artifacts. The ProMax ${ }^{\circledR}$ CBCT systems (Planmeca Oy, Helsinki, Finland) have the artifact reduction algorithm. ${ }^{13}$ In order to prevent unnecessary treatment due to false positive results, it is imperative to know the details of artifacts caused by root filling materials as well as methods to minimize them. ${ }^{12,13}$

To the best of our knowledge, studies on the efficacy of artifact removal software in enhancing the detection of VRFs of endodontically treated teeth on CBCT scans are limited. The aim of this study was therefore to assess the efficacy of an artifact removal program in detecting VRFs in endodontically treated teeth on CBCT scans.

\section{Material and methods}

This study evaluated 70 single-canal teeth extracted for orthodontic treatment or severe periodontal disease (the number of approval from the ethics committee: IR.UMSHA.REC.1396.687). Multi-rooted and broken teeth, and those with root caries were excluded. The teeth were disinfected using $2 \%$ sodium hypochlorite solution. The root canals were instrumented by an endodontist using a stainless steel K-file size 40 (Dentsply, Ballaigues, Switzerland) and the passive step-back technique, and were filled with gutta-percha points size 40 (Pumadent Co., Ltd., Tianjin, China) using the lateral compaction technique. Next, the gutta-percha sealer was removed from the coronal third of the canal with a Gates-Glidden drill size 3 (Mani Inc., Utsunomiya, Japan). Teeth with a complete root fracture that occurred during root canal preparation were excluded. The teeth were then randomly divided into 2 groups $(\mathrm{n}=35)$. Cracks were induced in the experimental group by introducing a wedge into the canal and tapping gently with a hammer; the other group remained untouched as a control group. A fresh bovine rib bone was used in this study due to its resemblance to the alveolar bone. The ribs were cut into bone segments measuring $15 \mathrm{~mm}$ in length, $10 \mathrm{~mm}$ in width and $20 \mathrm{~mm}$ in height.

The teeth from each group were randomly mounted in rows ( 7 teeth in each row) in 10 bovine ribs in a curved fashion to simulate the dental arch, and then fixed with dental wax. The bovine ribs were coated with 3 layers of wax to simulate soft tissue (Fig. 1).

The teeth mounted in each bovine rib were subjected to CBCT using the following CBCT systems:

- NewTom ${ }^{\circledR} 3 G$ (Quantitative Radiology, Verona, Italy) with 6-inch FOV, $10.65 \mathrm{~mA}$ and $90 \mathrm{kVp}$;

- ProMax 3D (Planmeca Oy) with $8 \mathrm{~cm} \times 8 \mathrm{~cm}$ FOV, $14 \mathrm{~mA}$, time of $12 \mathrm{~s}$, and $84 \mathrm{kVp}$, with and without the metal artifact reduction (MAR) algorithm;

- Cranex ${ }^{\circledR}$ 3D (Soredex, Tuusula, Finland) with $6 \mathrm{~cm} \times 8 \mathrm{~cm}$ FOV, $4 \mathrm{~mA}$, time of $6.1 \mathrm{~s}$, and $110 \mathrm{kVp}$, with and without the MAR algorithm.

The CBCT images obtained by means of the NewTom $3 G$ system were evaluated in 2 modes: with and without the MATLAB (www.mathworks.com) image processing software (Fig. 2,3).

The CBCT images obtained using ProMax 3D were evaluated in 3 modes: with and without the artifact removal
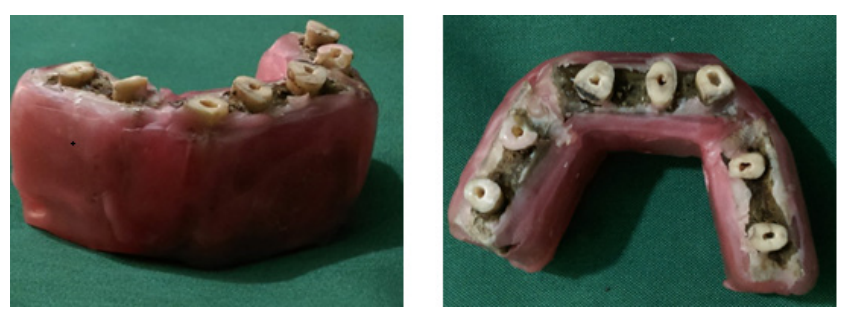

Fig. 1. Tooth placement 


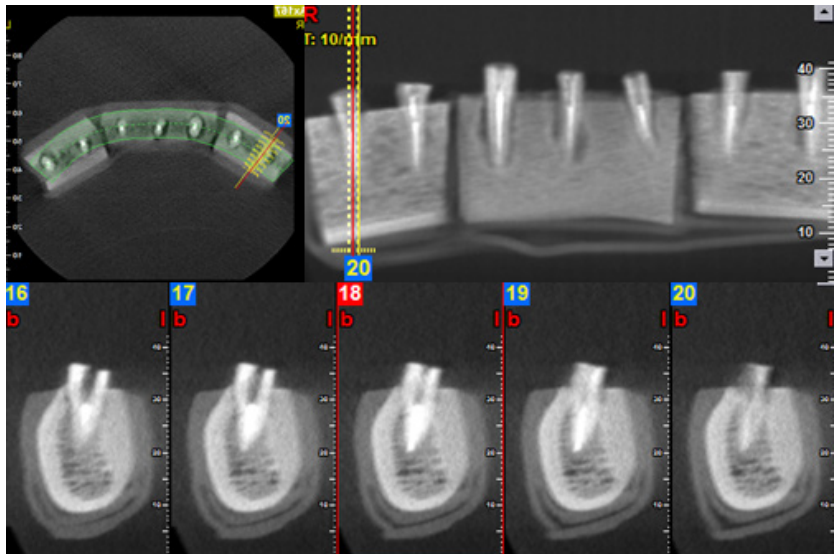

Fig. 2. NewTom 3G image

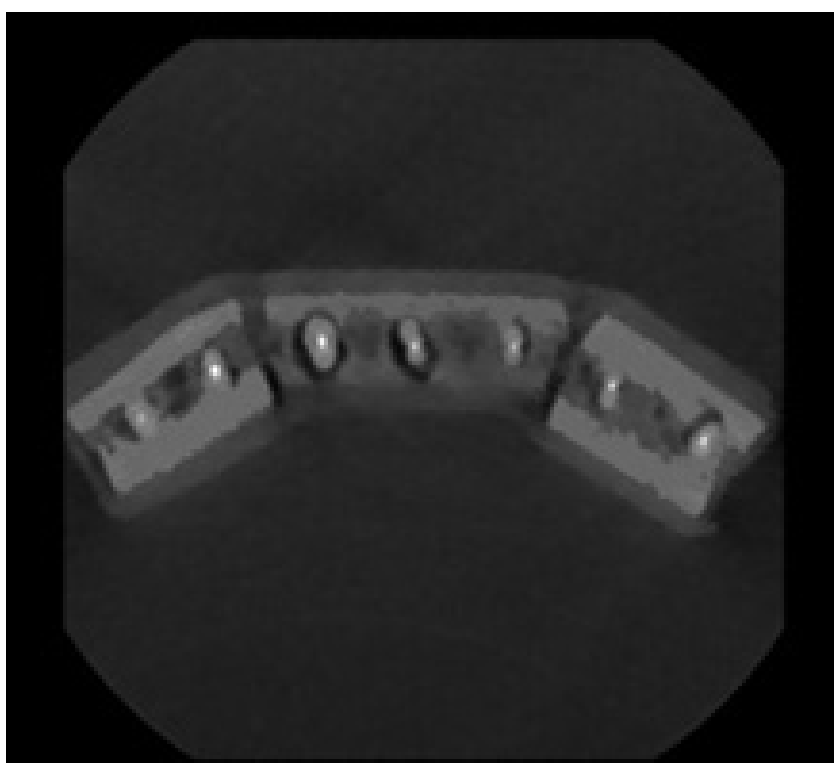

Fig. 3. NewTom 3G image with the MATLAB processing software

feature of the system, and also by applying the MATLAB artifact removal software (Fig. 4-6).

The CBCT images obtained with Cranex 3D were evaluated in 3 modes: with and without the artifact removal feature, and by applying the MATLAB artifact removal software (Fig. 7-9).

The CBCT scans of each group were assessed by 2 oral and maxillofacial radiologists with 10 years of clinical

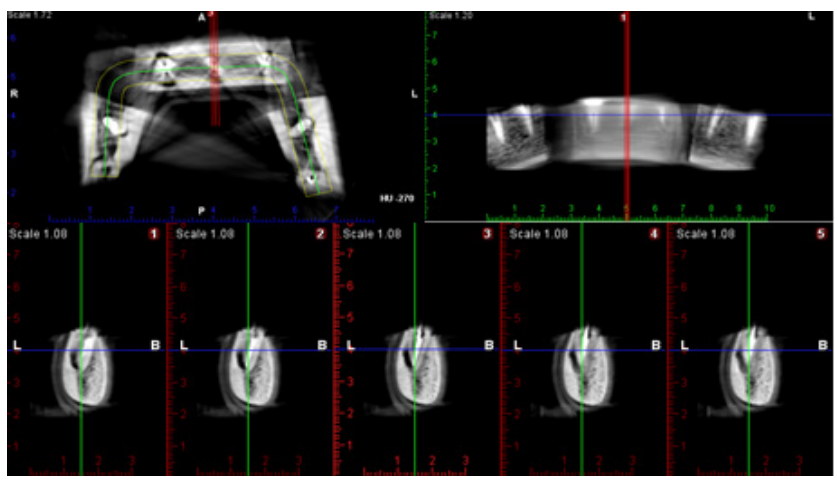

Fig. 4. ProMax 3D image

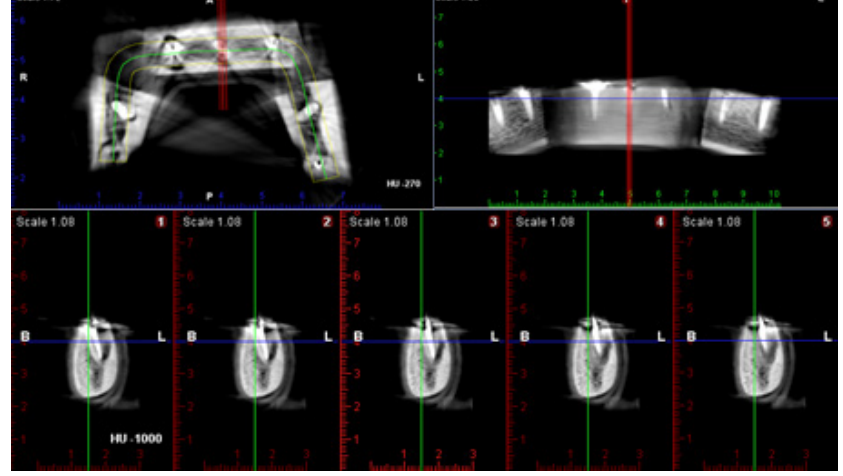

Fig. 5. ProMax 3D image with the metal artifact reduction (MAR) algorithm

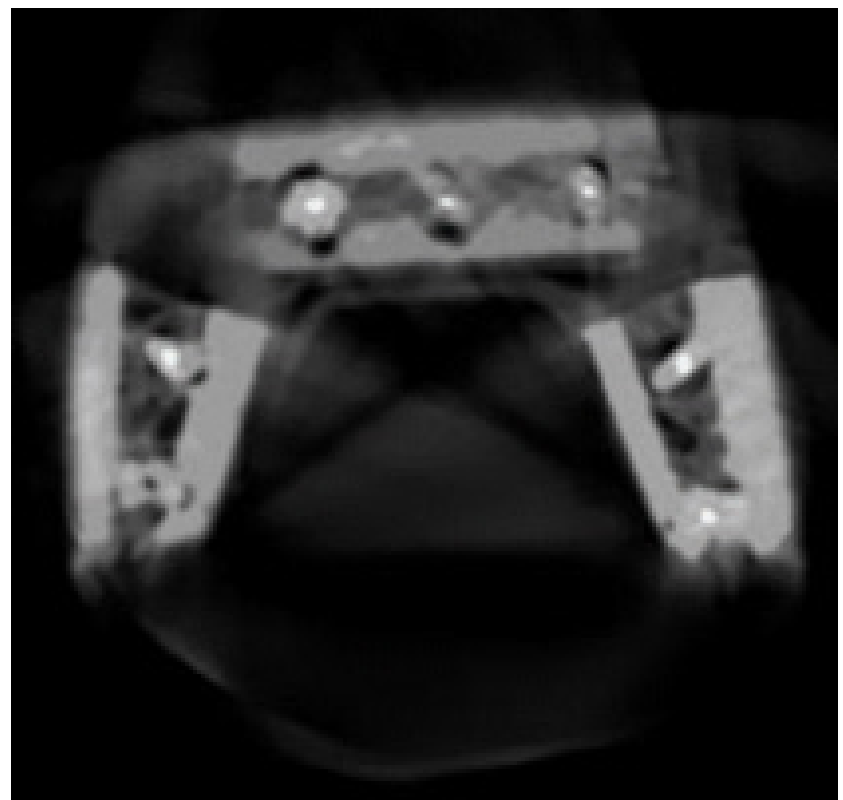

Fig. 6. ProMax 3D image with the MATLAB processing software

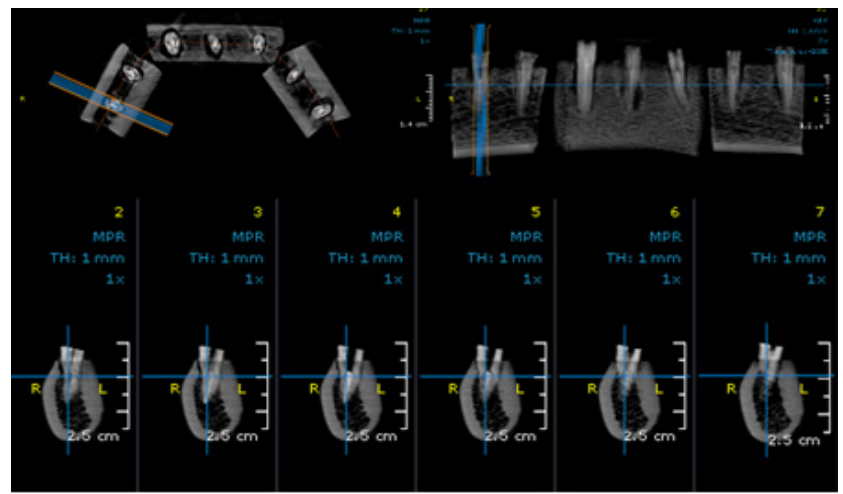

Fig. 7. Cranex 3D image

experience in a double-blind fashion on a 20-inch monitor (200P; LG Corporation, Seoul, South Korea) in a semidark room. The observers independently evaluated the images in the axial, coronal and sagittal planes by scrolling the mouse, and also assessed the cross-sectional images with a slice thickness of $1 \mathrm{~mm}$ and intervals of $0.5 \mathrm{~mm}$. The observers were allowed to adjust the density and contrast of the images, and to use a magnification tool. 


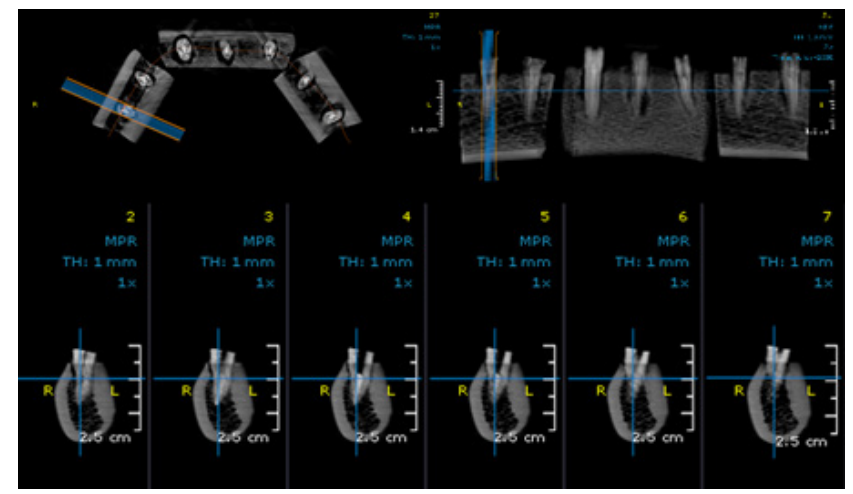

Fig. 8. Cranex 3D image with the metal artifact reduction (MAR) algorithm

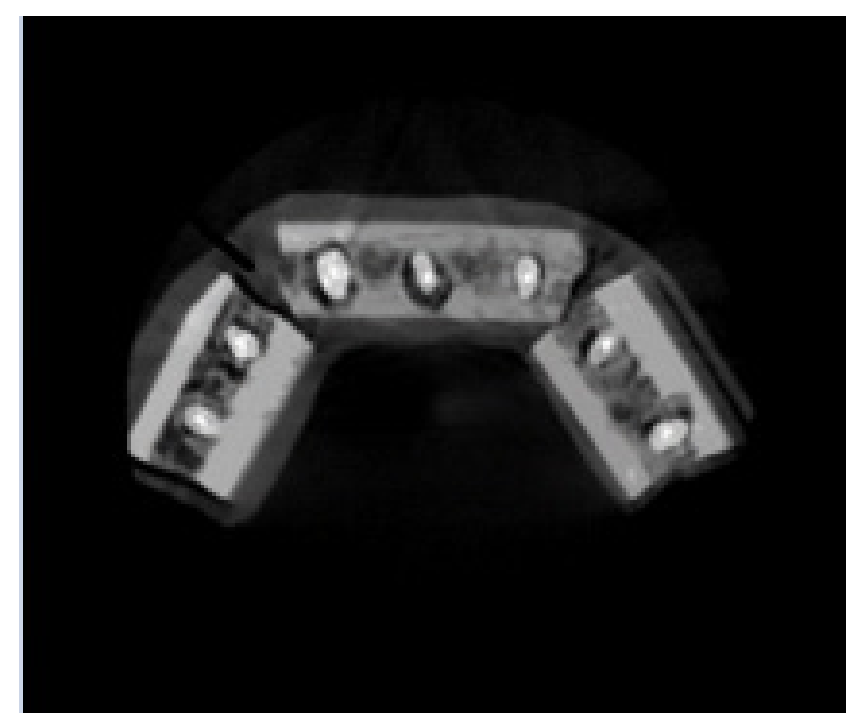

Fig. 9. Cranex 3D image with the MATLAB processing software

The results were reported as the presence or absence of VRF, and recorded on a checklist.

The data was entered into IBM SPSS Statistics for Windows software, v. 24 (IBM Corp., Armonk, USA) and analyzed using the $\chi^{2}$ test and McNemar's test. The weighted $\kappa$ coefficient was also calculated to determine the level of inter-observer agreement. The level of significance was set at 0.01 .

\section{Results}

As shown in Table 1, the 2 observers had a significant agreement according to the $\kappa$ statistic. The use of the MATLAB and MAR software programs improved the sensitivity and specificity of the detection of VRFs. Cranex 3D with the MATLAB software yielded the highest sensitivity (85\%) and specificity (80\%), whereas ProMax 3D showed the lowest sensitivity (48\%) and specificity (51\%) (Table 2). According to the $X^{2}$ test, the difference between NewTom 3G and NewTom 3G (MATLAB) was not significant $(p=0.119)$. No significant differences were noted between ProMax 3D and ProMax 3D (MATLAB) $(p=0.455)$, ProMax 3D and ProMax 3D (MAR) $(p=0.980)$, or Cranex $3 \mathrm{D}$ and Cranex 3D (MAR) $(p=0.060)$. However, the difference between Cranex 3D and Cranex 3D (MATLAB) was significant ( $p=0.039)$ (Table 3$)$.

The independent $t$-test was used to assess the effect of the tooth position on the detection of VRFs. It was also applied to compare the mean area under the curve (AUC) in the anterior and posterior teeth, which showed no significant difference $(p=0.137)$ (Table 4).

Table 1. Inter-observer agreement for different cone-beam computer tomography (CBCT) systems determined by calculating the Cohen's $k$ coefficient

\begin{tabular}{|l|c|}
\multicolumn{1}{|c|}{ System/Mode } & Coefficient of agreement \\
NewTom 3G & 0.910 \\
NewTom 3G (MATLAB) & 1 \\
ProMax 3D & 1 \\
ProMax 3D (MAR) & 1 \\
ProMax 3D (MATLAB) & 0.910 \\
Cranex 3D & 0.910 \\
Cranex 3D (MAR) & 1 \\
Cranex 3D (MATLAB) & 1 \\
\hline
\end{tabular}

MAR - metal artifact reduction.

Table 2. Sensitivity, specificity, false positive, and false negative values for the 3 cone-beam computer tomography (CBCT) systems assessed in the study

\begin{tabular}{|c|c|c|c|c|c|c|c|}
\hline System/Mode & $\begin{array}{c}\text { Sensitivity } \\
{[\%]}\end{array}$ & $\begin{array}{c}\text { Specificity } \\
{[\%]}\end{array}$ & $\begin{array}{c}\text { False negative } \\
{[\%]}\end{array}$ & $\begin{array}{c}\text { False positive } \\
{[\%]}\end{array}$ & mean AUC & $\begin{array}{c}S E \\
(A \cup C)\end{array}$ & $\begin{array}{c}95 \% \mathrm{Cl} \\
\text { (AUC) }\end{array}$ \\
\hline NewTom 3G & 65 & 65 & 34 & 34 & 0.657 & 0.071 & $(0.770-0.543)$ \\
\hline NewTom 3D (MATLAB) & 77 & 71 & 22 & 28 & 0.743 & 0.068 & $(0.846-0.639)$ \\
\hline ProMax 3D & 48 & 51 & 51 & 48 & 0.557 & 0.059 & $(0.674-0.439)$ \\
\hline ProMax 3D (MATLAB) & 71 & 62 & 28 & 37 & 0.614 & 0.058 & $(0.727-0.500)$ \\
\hline ProMax 3D (MAR) & 57 & 60 & 42 & 40 & 0.586 & 0.060 & $(0.703-0.468)$ \\
\hline Cranex 3D & 68 & 68 & 31 & 31 & 0.686 & 0.056 & $(0.795-0.576)$ \\
\hline Cranex 3D (MATLAB) & 85 & 80 & 14 & 20 & 0.829 & 0.045 & $(0.917-0.740)$ \\
\hline Cranex 3D (MAR) & 82 & 70 & 17 & 21 & 0.743 & 0.052 & $(0.844-0.641)$ \\
\hline
\end{tabular}

AUC - area under curve; SE - standard error; $\mathrm{Cl}$ - confidence interval. 
Table 3. Differences between the 3 cone-beam computer tomography $(\mathrm{CBCT})$ systems analyzed with the $x^{2}$ test $(p<0.01)$

\begin{tabular}{|l|c|c|c|}
\multicolumn{1}{c|}{ System/Mode } & mean AUROC & $\begin{array}{c}\text { SE } \\
\text { (AUROC) }\end{array}$ & $p$-value \\
\hline NewTom 3G & 0.715 & 0.055 & - \\
NewTom 3D (MATLAB) & 0.824 & 0.058 & 0.119 \\
ProMax 3D & 0.616 & 0.056 & - \\
ProMax 3D (MATLAB) & 0.549 & 0.052 & 0.455 \\
ProMax 3D (MAR) & 0.618 & 0.059 & 0.980 \\
Cranex 3D & 0.753 & 0.060 & - \\
Cranex 3D (MATLAB) & 0.906 & 0.081 & $0.039^{*}$ \\
Cranex 3D (MAR) & 0.847 & 0.052 & 0.060 \\
\hline
\end{tabular}

AUROC - area under the receiver operating characteristic (ROC) curves; * statistically significant.

Table 4. Area under the receiver operating characteristic (ROC) curves for the anterior and posterior teeth $(p<0.01)$

\begin{tabular}{|c|c|c|c|c|}
\hline $\begin{array}{c}\text { Position } \\
\text { of the } \\
\text { teeth }\end{array}$ & mean AUROC & $\begin{array}{c}\text { SD } \\
\text { (AUROC) }\end{array}$ & t-test & $p$-value \\
\hline $\begin{array}{l}\text { Anterior } \\
\text { Posterior }\end{array}$ & 0.602 & 0.149 & $-1 / 557$ & 0.137 \\
\hline
\end{tabular}

SD - standard deviaton.

\section{Discussion}

The detection of VRFs is challenging, because false negative diagnoses lead to periodontal disease over time, whereas false positive diagnoses lead to unnecessary dental treatment. ${ }^{15,16}$

The main limitations of periapical radiography include the superimposition of anatomical structures and the poor visualization of VRFs. ${ }^{17,18}$ Researchers have long been searching for modalities alternative to periapical radiography and $\mathrm{CBCT}$ has been introduced for this purpose.${ }^{19}$ Considering the need for further investigation on this topic as well as the fact that CBCT systems may perform differently due to the differences in their FOV, voxel size and detectors, this study compared the efficacy of 3 CBCT systems, namely NewTom 3G, ProMax 3D and Cranex 3D, with or without the artifact removal software, in the detection of VRFs. The results showed that the sensitivity values for NewTom 3G, ProMax 3D and Cranex 3D were 65\%, 48\% and 68\%, respectively; after applying the MATLAB software, they were $77 \%$, $71 \%$ and $85 \%$, respectively. Also, the sensitivity values for ProMax 3D and Cranex 3D after applying the MAR algorithm were $57 \%$ and $82 \%$, respectively. The specificity values for NewTom 3G, ProMax 3D and Cranex 3D were $65 \%, 51 \%$ and $68 \%$, respectively; after applying MATLAB, they were $71 \%, 62 \%$ and $80 \%$, respectively. The specificity values for ProMax 3D and Cranex 3D after applying the MAR algorithm were $60 \%$ and $70 \%$, respectively.
The anterior/posterior position of the teeth had no effect on the diagnostic efficacy of the systems in detecting the VRFs assessed in the study.

Hekmatian et al. evaluated the effect of the presence of gutta-percha on the detection of VRFs on CBCT images and reported that the presence of gutta-percha in the canal decreased the ability to detect VRFs. ${ }^{20}$ Kamburoğlu et al. reported that dark areas around guttapercha on the CBCT images of endodontically treated mandibular premolars caused false positive results and led to misdiagnoses of root fracture. ${ }^{21}$ Hassan et al. evaluated the effect of root filling materials on the detection of VRFs on CBCT images, and reported that they significantly decreased the accuracy and sensitivity of the detection of VRFs. ${ }^{22}$

The manufacturers of CBCT systems are searching for methods to enhance image quality by developing image processing tools, such as the MAR algorithms. ${ }^{23,24}$ The MAR algorithm is a post-processing program which is applied during image reconstruction and has no effect on image acquisition. The MAR algorithm decreases or eliminates artifacts. This kind of software increases the contrast-to-noise ratio; it also prolongs the image reconstruction time. ${ }^{3,25}$ Tofangchiha et al. evaluated the effect of the artifact reduction algorithm on the detection of VRFs on CBCT scans. ${ }^{26}$ They scanned the teeth with ProMax 3D. The results showed that the sensitivity and specificity values for VRF detection without the artifact reduction algorithm were $54 \%$ and $61 \%$, which changed to $57 \%$ and $69 \%$, respectively, after applying the artifact reduction algorithm. In fact, applying this algorithm did not increase the sensitivity or specificity of VRF detection. ${ }^{26}$ In the present study, the sensitivity and specificity values for detecting VRFs were $48 \%$ and 51\% for ProMax $3 \mathrm{D}$ without the artifact reduction algorithm, and $57 \%$ and $60 \%$, respectively, after applying the algorithm. This was consistent with the results reported by Tofangchiha et al. ${ }^{26}$

Vasconcelos et al. evaluated the artifacts of endodontically treated teeth on CBCT scans taken by means of different systems - Cranex 3D, Accuitomo ${ }^{\circledR} 1703 \mathrm{D}$, WhiteFox ${ }^{\circledR}$ $3 \mathrm{D}$, and Scanora ${ }^{\circledR} 3 \mathrm{D}$ - and showed that Cranex 3D had a significantly higher prevalence of artifacts (75\%). ${ }^{11}$ The application of the artifact reduction algorithm did not significantly improve the results. ${ }^{11}$ In the present study, the prevalence of artifacts in Cranex 3D was smaller than in the case of other systems and the diagnostic value of this system for the detection of VRFs was higher than that of other systems. The difference between our findings and those reported by Vasconcelos et al. may be due to the different $\mathrm{CBCT}$ systems evaluated and the very high resolution of Accuitomo 170 3D (a voxel size of $0.08 \mathrm{~mm}^{3}$ ) compared to Cranex 3D (a voxel size of $0.2 \mathrm{~mm}^{3}$ ). ${ }^{11}$

Metska et al. evaluated the detection of VRFs on CBCT scans taken with Accuitomo 170 3D and NewTom 3G, and showed that the sensitivity and specificity values were $75 \%$ and $56 \%$, respectively, for NewTom $3 G$, and 
$100 \%$ and $80 \%$, respectively, for Accuitomo $170 .{ }^{27}$ In the present study, the sensitivity and specificity values for NewTom $3 G$ were $65 \%$ and $65 \%$, respectively, which was consistent with the results of the study by Metska et al. ${ }^{27}$ Bechara et al. scanned the teeth using the Master ${ }^{\circledR} 3 \mathrm{D}$ and ProMax 3D CBCT systems, and the results showed that ProMax 3D without software had the highest accuracy for detecting VRFs and Master 3D with software the lowest. ${ }^{13}$ The accuracy of both systems significantly decreased after applying the artifact removal software; the accuracy of ProMax 3D with and without software was higher than that of Master 3D. ${ }^{13}$

Queiroz et al. assessed the effect of the CBCT MAR algorithm for different dental materials and indicated that the application of the algorithm caused a significant reduction in the prevalence of artifacts around dental alloys, but had no significant effect on artifact reduction around gutta-percha. ${ }^{23}$ In the present study, the application of the MAR algorithm did not significantly decrease the prevalence of artifacts around gutta-percha, which was in agreement with the results of previous studies. ${ }^{13,23}$ The atomic numbers of the main constituents of dental amalgam - silver (Ag) and mercury $(\mathrm{Hg})$ - are 47 and 80, respectively, whereas gutta-percha is composed of zinc oxide, with the atomic number of zinc being 30, and isoprene rubber, with its components of much lower atomic numbers than in the case of amalgam. As a result, the number of artifacts caused by gutta-percha is smaller than of those caused by amalgam and other dental alloys, and therefore the MAR algorithm could not detect and minimize them. ${ }^{23}$

Johari et al. evaluated the detection of VRFs in sound premolars and endodontically treated teeth using a probabilistic neural network (PNN). ${ }^{28}$ The teeth were scanned with the Kodak 2200 intraoral X-ray system and the NewTom VGi CBCT system. The results showed that the use of PNN is suitable for detecting VRFs in endodontically treated teeth. ${ }^{28}$ De Martin e Silva et al. evaluated the effect of using filtering software for CBCT images (i-CAT ${ }^{\circledR}$ next generation) on the detection of VRFs in teeth with metal posts. ${ }^{16}$ The results revealed that the presence of guttapercha and metal posts decreased the accuracy of VRF detection, and that applying filtering software could not enhance the detection of VRFs. ${ }^{16}$

The MATLAB software used in the present study enhanced the detection of VRFs on images taken with the Cranex 3D, ProMax 3D and NewTom 3G CBCT systems to some extent. The difference caused by the application of MATLAB was significant for Cranex 3D, but it was not significant for the other $2 \mathrm{CBCT}$ systems. The differences between our results and those of previous studies may be attributed to the fact that different software programs and CBCT systems were used.

When polychromatic X-ray beams pass through an object, low-energy photons are absorbed to a greater extent than high-energy photons. This phenomenon increases the mean energy of X-ray beams and leads to beam hardening. The low-energy X-ray beams interact with materials with high atomic numbers and cause a further hardening of the beam. An increased voltage $[\mathrm{kVp}]$ increases the energy and penetration depth of the X-ray beam. Thus, increasing the voltage decreases beam hardening, and consequently the number of metal artifacts. ${ }^{29}$ Panjnoush et al. evaluated the effects of various exposure settings on the level of metal artifacts when using different imaging modalities and concluded that increasing the voltage decreases the number of metal artifacts. ${ }^{30}$ In the present study, Cranex 3D had the highest accuracy for detecting VRFs, followed by NewTom 3G and ProMax $3 \mathrm{D}$ in a descending order. Considering a lower voltage of ProMax 3D (84 kVp) compared to NewTom 3G $(90 \mathrm{kVp})$ and Cranex 3D $(110 \mathrm{kVp})$, the prevalence of metal artifacts would be higher in ProMax 3D.

Artifacts on CBCT images are not equally distributed over FOV. The position of an object in FOV affects the amount of scatter radiation, and consequently the level of noise and image quality; placing an object in the center of FOV is important to achieve a high-quality image. ${ }^{31,32}$ In the present study, the simulated dental arch was in the center of FOV, and the anterior/posterior position of the teeth in the simulated dental arch had no significant effect on the detection of VRFs.

\section{Conclusions}

The results of this study revealed that applying the MAR algorithm had no positive effect on the detection of VRFs on CBCT images obtained with the Cranex 3D and ProMax 3D CBCT systems. The use of the MATLAB software enhanced the detection of VRFs on CBCT images generated by the Cranex 3D, ProMax 3D and NewTom 3G CBCT systems to some extent. Cranex 3D with the MATLAB software had the highest diagnostic accuracy for detecting VRFs, with sensitivity of $85 \%$ and specificity of $80 \%$.

\section{ORCID iDs}

Samira Saati (i) https://orcid.org/0000-0003-2460-774X Amir Eskandarloo (1) https://orcid.org/0000-0001-5997-8562 Alireza Falahi (i) https://orcid.org/0000-0001-7978-3201 Leili Tapak (1) https://orcid.org/0000-0002-4378-3143 Bahareh Hekmat (1) https://orcid.org/0000-0001-6185-1253

\section{References}

1. Queiroz PM, Oliveira ML, Groppo FC, Haiter-Neto F, Freitas DQ. Evaluation of metal artefact reduction in cone-beam computed tomography images of different dental materials. Clin Oral Investig. 2018;22(1):419-423.

2. Fox $A$, Basrani $B$, Lam EWN. The performance of a zirconium-based root filling material with artifact reduction properties in the detection of artificially induced root fractures using cone-beam computed tomographic imaging. J Endod. 2018;44(5):828-833. 
3. Queiroz PM, Groppo FC, Oliveira ML, Haiter-Neto F, Freitas DQ. Evaluation of the efficacy of a metal artifact reduction algorithm in different cone-beam computed tomography scanning parameters. Oral Surg Oral Med Oral Pathol Oral Radiol. 2017;123(6):729-734.

4. Eskandarloo A, Saati S, Ardakani MP, Jamalpour M, Gholi Mezerji NM, Akheshteh V. Diagnostic accuracy of three cone-beam computed tomography systems and periapical radiography for detection of fenestration around dental implants. Contemp Clin Dent. 2018;9(3):376-381.

5. likubo $M$, Nishioka T, Okura $S$, et al. Influence of voxel size and scan field of view on fracture-like artifacts from gutta-percha obturated endodontically treated teeth on cone-beam computed tomography images. Oral Surg Oral Med Oral Pathol Oral Radiol. 2016;122(5):631-637.

6. Shokri A, Lari S, Yousef F, Hashemi L. Assessment of the relationship between the maxillary sinus floor and maxillary posterior teeth roots using cone-beam computed tomography. J Contemp Dent Pract. 2014;15(5):618-622.

7. Brito-Júnior M, Santos L, Faria-e-Silva A, Pereira RD, Sousa-Neto MD. Ex vivo evaluation of artifacts mimicking fracture lines on conebeam computed tomography produced by different root canal sealers. Int Endod J. 2014;47(1):26-31.

8. Durack C, Patel S. Cone-beam computed tomography in endodontics. Braz Dent J. 2012;23(3):179-191.

9. Salemi F, Shokri A, Maleki FH, et al. Effect of field of view on detection of condyle bone defects using cone-beam computed tomography. J Craniofac Surg. 2016;27(3):644-648.

10. Dalili Kajan Z, Taramsari M, Khosravi Fard N, Khaksari F, Moghasem Hamidi F. The efficacy of metal artifact reduction mode in conebeam computed tomography images on diagnostic accuracy of root fractures in teeth with intracanal posts. Iran Endod J. 2018;13(1):47-53.

11. Vasconcelos KF, Nicolielo LF, Nascimento MC, et al. Artefact expression associated with several cone-beam computed tomographic machines when imaging root-filled teeth. Int Endod J. 2015;48(10):994-1000.

12. likubo M, Osano T, Sano T, et al. Root canal filling materials spread pattern-mimicking root fractures in dental CBCT images. Oral Surg Oral Med Oral Pathol Oral Radiol. 2015;120(4):521-527.

13. Bechara B, Alex McMahan C, Moore WS, Noujeim M, Teixeira FB, Geha $\mathrm{H}$. Cone-beam CT scans with and without artefact reduction in root fracture detection of endodontically treated teeth. Dentomaxillofac Radiol. 2013;42(5):20120245.

14. Schulze R, Heil U, Gross D, et al. Artefacts in CBCT: A review. Dentomaxillofac Radiol. 2011;40(5):265-273.

15. Khedmat S, Rouhi N, Drage N, Shokouhinejad N, Nekoofar $\mathrm{MH}$ Evaluation of three imaging techniques for the detection of vertical root fractures in the absence and presence of gutta-percha root fillings. Int Endod J. 2012;45(11):1004-1009.

16. De Martin e Silva D, Campos CN, Pires Carvalho AC, Devito KL. Diagnosis of mesiodistal vertical root fractures in teeth with metal posts: Influence of applying filters in cone-beam computed tomography images at different resolutions. J Endod. 2018;44(3):470-474.

17. Angelopoulos $C$, Aghaloo T. Imaging technology in implant diagnosis. Dent Clin North Am. 2011;55(1):141-158.

18. Eskandarloo A, Asl AM, Jalalzadeh M, et al. Effect of time lapse on the diagnostic accuracy of cone-beam computed tomography for detection of vertical root fractures. Braz Dent J. 2016;27(1):16-21.

19. Bagis N, Kolsuz ME, Kursun S, Orhan K. Comparison of intraoral radiography and cone-beam computed tomography for the detection of periodontal defects: An in vitro study. BMC Oral Health. 2015;15:64.

20. Hekmatian E, Karbasi Kheir M, Fathollahzade H, Sheikhi M. Detection of vertical root fractures using cone-beam computed tomography in the presence and absence of gutta-percha. ScientificWorldJournal. 2018;2018:1920946.

21. Kamburoğlu K, Murat S, Yüksel SP, Cebeci AR, Horasan S. Detection of vertical root fracture using cone-beam computerized tomography: An in vitro assessment. Oral Surg Oral Med Oral Pathol Oral Radiol Endodont. 2010;109(2):e74-e81.

22. Hassan B, Metska ME, Ozok AR, van der Stelt P, Wesselink PR. Detection of vertical root fractures in endodontically treated teeth by a conebeam computed tomography scan. J Endod. 2009;35(5):719-722.
23. Queiroz PM, Santaella GM, da Paz TD, Freitas DQ. Evaluation of a metal artefact reduction tool on different positions of a metal object in the FOV. Dentomaxillofac Radiol. 2017;46(3):20160366.

24. Maltz JS, Gangadharan B, Bose S, et al. Algorithm for X-ray scatter, beam-hardening, and beam profile correction in diagnostic (kilovoltage) and treatment (megavoltage) cone beam CT. IEEE Trans Med Imaging. 2008;27(12):1791-1810.

25. Bechara B, McMahan CA, Geha H, Noujeim M. Evaluation of a conebeam CT artefact reduction algorithm. Dentomaxillofac Radiol. 2012;41(5):422-428.

26. Tofangchiha M, Adel M, Tavakolian E, Ghaffari P, Jabbarian R. The effect of metal artifacts reduction algorithm on diagnostic accuracy of vertical root fracture by cone-beam computed tomography, an in vitro study. Sch J Dent Sci. 2017;4(3):115-120.

27. Metska ME, Aartman IHA, Wesselink PR, Özok AR. Detection of vertical root fractures in vivo in endodontically treated teeth by cone-beam computed tomography scans. J Endod. 2012;38(10):1344-1347.

28. Johari M, Esmaeili F, Andalib A, Garjani S, Saberkari H. Detection of vertical root fractures in intact and endodontically treated premolar teeth by designing a probabilistic neural network: An ex vivo study. Dentomaxillofac Radiol. 2017;46(2):20160107.

29. Pauwels R, Araki K, Siewerdsen J, Thongvigitmanee SS. Technical aspects of dental CBCT: State of the art. Dentomaxillofac Radiol. 2015;44(1):20140224

30. Panjnoush $M$, Kheirandish $Y$, Kashani PM, Fakhar HB, Younesi F, Mallahi M. Effect of exposure parameters on metal artifacts in conebeam computed tomography. J Dent (Tehran). 2016;13(3):143-150.

31. Taylor C. Evaluation of the effects of positioning and configuration on contrast-to-noise ratio in the quality control of a 3D Accuitomo 170 dental CBCT system. Dentomaxillofac Radiol. 2016;45(5):20150430.

32. Shokri A, Shakibaei Z, Langaroodi AJ, Safaei M. Evaluation of the mandibular canal visibility on cone-beam computed tomography images of the mandible. J Craniofac Surg. 2014;25(3):e273-e277. 